\title{
Blood Loss during Flexible Bronchoscopy: A Prospective Observational Study
}

\author{
Ighsaan M. Carr ${ }^{\mathrm{a}}$ Coenraad F.N. Koegelenberg ${ }^{\mathrm{a}}$ \\ Florian von Groote-Bidlingmaier ${ }^{\mathrm{a}} \quad$ Abdurasiet Mowlana $^{\mathrm{a}}$ Kim Silos $^{\mathrm{a}}$ \\ Thijs Haverman $^{a}$ Andreas H. Diacon ${ }^{a, b}$ Chris T. Bolliger $^{a}$ \\ ${ }^{a}$ Division of Pulmonology, Department of Medicine, and ${ }^{b}$ Division of Medical Physiology, Department of \\ Biomedical Sciences, University of Stellenbosch and Tygerberg Academic Hospital, Cape Town, South Africa
}

\section{Key Words}

Flexible bronchoscopy $\cdot$ Bleeding $\cdot$ Blood loss

\begin{abstract}
Background: Haemorrhage remains a complication of flexible bronchoscopy. Objectives: We aimed to measure the actual blood loss in patients at low risk of bleeding and to assess its association with the underlying pulmonary pathology, superior vena cava (SVC) syndrome, procedure(s) performed and laboratory values. Methods: We screened all patients scheduled for flexible bronchoscopy and enrolled 234 subjects over 18 months. Subjects with a history of haemorrhagic tendency, platelets $<20 \times 10^{3} / \mu \mathrm{l}$, a history of anti-coagulation or anti-platelet therapy and a history or clinical evidence of liver failure were excluded. Blood loss during the procedure was measured from aspirated secretions with a haemoglobin detector and categorised into minimal $(<5 \mathrm{ml})$, mild $(5-20 \mathrm{ml})$, moderate $(20-100 \mathrm{ml})$ and severe bleeding ( $>100 \mathrm{ml}$ ). Results: Overall, 210 subjects had minimal, 19 had mild and 5 had moderate bleeding. No subject experienced severe blood loss. Patients with SVC syndrome had the highest mean blood loss $(6.0 \mathrm{ml})$ when compared to bronchogenic carcinoma without SVC syndrome $(p=0.033)$ and other diagnosis $(p=0.026)$. The blood loss with trans-bronchial needle aspiration (TBNA, mean $3.4 \mathrm{ml}$ )
\end{abstract}

was significantly less than with TBNA combined with endobronchial or transbronchial biopsy (mean $5.0 \mathrm{ml}, \mathrm{p}<0.001$ ). Anaemia, a platelet count of $25-155 \times 10^{3} / \mu \mathrm{l}$ and an international normalized ratio of $>1.3$ were not associated with an increased risk of bleeding. Conclusions: We found no severe bleeding in this cohort preselected to have a low clinical risk of bleeding. Moreover, our data suggest that clinical screening and a platelet count $\geq 20 \times 10^{3} / \mu$ l alone may be sufficient to identify low-risk patients.

Copyright $\odot 2012$ S. Karger AG, Basel

\section{Introduction}

Bleeding is a known complication of flexible bronchoscopy, although mostly not life-threatening $[1,2]$. The ability to accurately assess the amount of bleeding occurring during bronchoscopy is often difficult for several reasons including the insensible bleeding into the bronchial tree and the inaccurate estimation of the volume of blood aspirated [3].

Bleeding during bronchoscopy is often only estimated by direct observation. This is in contrast to surgical interventions where blood loss is often estimated using gravimetric measures, such as the number of swabs soiled with blood, to calculate significant amounts of blood loss

\section{KARGER \\ Fax +4161306 1234 \\ E-Mail karger@karger.ch}

www.karger.com
(C) $2012 \mathrm{~S}$. Karger AG, Basel

$0025-7931 / 12 / 0844-0312 \$ 38.00 / 0$

Accessible online at:

www.karger.com/res
Prof. Chris T. Bolliger

Department of Medicine, Division of Pulmonology, University of Stellenbosch PO Box 19063

Tygerberg, 7505, Cape Town (South Africa)

Tel. +27 21938 9423, E-Mail ctb@ sun.ac.za 
Table 1. Exclusion criteria

Active pulmonary bleeding (haemoptysis)

History, family history or physical evidence of bleeding tendencies (petechiae, purpura, ecchymosis, haematoma)

History of anti-platelet therapy (aspirin, clopidogrel)

History of anti-coagulation therapy (warfarin, heparin)

History or physical evidence of liver disease (hepatitis, cirrhosis, hepatomegaly, ascites, jaundice)

Platelet count $<20 \times 10^{3} / \mu \mathrm{l}$ ically screened, i.e. an accurate history has been obtained, a physical examination and full blood count including a platelet count have been conducted and they are deemed to be at low risk. All other blood tests were done for post hoc analysis to assess if there was an association with bleeding during bronchoscopy. A secondary aim was to assess the value of standardised clinical screening in negating the need for routine coagulation studies prior to bronchoscopy and the association between bleeding and the underlying pulmonary pathology including superior vena cava (SVC) syndrome.

\section{Methods}

\section{Study Population}

All adult patients referred for bronchoscopy to the Division of Pulmonology at Tygerberg Academic Hospital during the period from November 2008 to April 2010 were potential candidates for this observational study. All patients older than 18 years that gave informed consent as well as those subjects younger than 18 years with a guardian's consent were enrolled, unless excluded by one of the criteria listed in table 1 . Tygerberg hospital is a 1,200-bed academic facility in Cape Town, South Africa. It is one of two referral centers in the city and renders a tertiary service to a population of about 1.5 million. The study was approved by the Stellenbosch University Research Ethics committee (study number N08/05/150).

\section{Bronchoscopic Procedures}

Experienced bronchoscopists performed the procedures with the assistance of at least one physician and two bronchoscopy nurses at the bronchoscopy theatre of Tygerberg Hospital. The procedures performed included bronchial washing (BW), bronchial brushing (BB), broncho-alveolar lavage (BAL), trans-bronchial needle aspiration (TBNA), TBB and EBB.

\section{Clinical Screening and Special Investigations}

A clinical history including screening questions for bleeding tendencies was taken, and a thorough physical examination was done for each of the subjects selected for this study. All patients were included, provided the investigation team members were all present, i.e. not all patients at the institution were included. All demographic data were recorded. Blood tests performed within $48 \mathrm{~h}$ prior to the bronchoscopy included routine coagulation studies, consisting of a partial thromboplastin time (PTT) and an international normalized ratio (INR). Measurement of a full blood count, blood urea and creatinine were also performed.

Thrombocytopaenia, for the purpose of this study, was defined as a platelet count of $<155 \times 10^{3} / \mu$ l. Investigators have previously suggested a platelet count of at least $50 \times 10^{3} / \mu$ l to be suitable for a bronchoscopy that includes TBNA or BB $[1,5]$. However, due to the lack of data regarding a significant bleeding risk in subjects with a platelet count of $<50 \times 10^{3} / \mu \mathrm{l}$, we decided to lower the acceptable platelet count to $\geq 20 \times 10^{3} / \mu$ l, but not any further, as it has previously been recommended that TBB are contraindicated when platelet counts are $<20 \times 10^{3} / \mu 1$ [5]. 
A bronchoscopist blinded to the screening history, clinical examination and blood results (performed by the attending medical registrar) performed the bronchoscopy along with the required interventions at his or her own discretion. The exception was if the subject had a platelet count of $\leq 20 \times 10^{3} / \mu$ l, then the bronchoscopist was informed. The amount of blood lost was determined immediately after the procedure. During the bronchoscopy, any visible blood was actively suctioned via the bronchoscope into a separate specimen-collection container attached to the suctioning apparatus. The volume of the mixed blood and lavage fluid (VM) aspirated via the bronchoscope was measured in milliliters and recorded for each subject. The haemoglobin $(\mathrm{Hb})$ concentration of this mixture ( $\mathrm{HbM})$ was then measured using a mobile, hand-held $\mathrm{Hb}$ detector device (HemoCue, Ängelholm, Sweden). This apparatus measures $\mathrm{Hb}$ concentrations as low as $0.3 \mathrm{~g} / \mathrm{dl}$. The Hb concentration of the patient's blood (HbP) was determined as part of the full blood count prior to the procedure. Based on a formula previously used in a similar study, the volume of blood loss was then calculated (volume of blood loss $=\mathrm{VM} \times$ $\mathrm{HbM} / \mathrm{HbP}$ ) [3]. Bleeding was arbitrarily categorised into minimal $(<5 \mathrm{ml})$, mild $(5-20 \mathrm{ml})$, moderate $(>20-100 \mathrm{ml})$ and severe $(>100$ $\mathrm{ml})$.

\section{Statistical Methods}

Due to the wide variation in the actual frequency and severity of bleeding from previous data in this population of subjects deemed to have a low risk of bleeding, a sufficiently powered study would have a sample size in the thousands (not feasible to investigate at a single centre). We therefore intended to conduct an observational study with a planned analysis after at least 250 subjects or 18 months (whichever came first). We intended including most of the bronchoscopic interventions conducted in our unit in this observational study. The study would be terminated at this stage if it were clearly evident from the data that there was a very low incidence of bleeding. Descriptive statistics using $\chi^{2}$ and the Fisher exact test of proportional data were performed. A p value of $<0.05$ was considered to be significant and data was analysed as a mean.

\section{Results}

Study Population Demographics and Disease Profiles

A total of 234 patients (table 2) were included in the study (136 males and 98 females, mean age 53.2 years, range 15-87 years) (fig. 1). A large proportion of these subjects $(40.6 \%, \mathrm{n}=95)$ were being investigated for primary lung carcinoma, either with or without metastatic lung disease. Twelve subjects had a confirmed primary diagnosis of a malignancy other than bronchogenic carcinoma. These included squamous-cell carcinoma of the tongue, transitional-cell carcinoma of the bladder, tracheal carcinoma, diffuse large B-cell lymphoma, Hodgkin's lymphoma, non-Hodgkin's lymphoma, acute myeloid leukaemia and primary breast carcinoma. A further 5 subjects had clinical features of SVC syndrome.
Table 2. Demographics, clinical diagnosis and laboratory parameters with associated blood loss ranges and mean values

\begin{tabular}{|c|c|c|c|c|}
\hline & $\begin{array}{l}\text { Subjects } \\
(\mathrm{n}=234)\end{array}$ & $\begin{array}{l}\text { Blood } \\
\text { loss, ml } \\
\text { (range) }\end{array}$ & $\begin{array}{l}\text { Blood } \\
\text { loss, } \mathrm{ml} \\
\text { (mean) }\end{array}$ & $\begin{array}{l}\mathrm{p} \\
\text { value }\end{array}$ \\
\hline \multicolumn{5}{|l|}{ Disease profile } \\
\hline $\mathrm{BC}$ & 95 & $0-23.4$ & 1.6 & $0.033^{\mathrm{a}}$ \\
\hline Other diagnosis & 12 & $0-14.7$ & 1.5 & $0.026^{\mathrm{b}}$ \\
\hline SVC syndrome $+B C$ & 5 & $0-16.3$ & 6.0 & \\
\hline Pneumonia & 22 & $0-6.9$ & 1.9 & $0.728^{\mathrm{b}}$ \\
\hline HIV & 19 & $0-6.9$ & 1.9 & $0.951^{\mathrm{c}}$ \\
\hline \multicolumn{5}{|l|}{ Laboratory parameters } \\
\hline \multicolumn{5}{|l|}{$\mathrm{Hb}$} \\
\hline$<10 \mathrm{~g} / \mathrm{dl}$ & 52 & $0-23.4$ & 2.3 & \\
\hline$\geq 10 \mathrm{~g} / \mathrm{dl}$ & 182 & $0-32.0$ & 1.9 & 0.551 \\
\hline \multicolumn{5}{|l|}{ Platelet count } \\
\hline$<155 \times 10^{3} / \mu \mathrm{l}$ & 11 & $0-3.3$ & $<1.0$ & \\
\hline$\geq 155 \times 10^{3} / \mu l$ & 223 & $0-32.0$ & 2.1 & 0.269 \\
\hline \multicolumn{5}{|l|}{ INR } \\
\hline No INR recorded & 26 & $0-6.3$ & 2.5 & \\
\hline Range (0.8-1.98) & 208 & $0-32.0$ & 1.9 & 0.527 \\
\hline$<1.3$ & 198 & $0-32.0$ & & 0.903 \\
\hline$\geq 1.3$ & 10 & & & \\
\hline \multicolumn{5}{|c|}{ PTT } \\
\hline$<30 \mathrm{~s}$ (range $30-64.7 \mathrm{~s}$ ) & 141 & $0-16.3$ & 1.4 & \\
\hline$\geq 30 \mathrm{~s}$ (range $30-64.7 \mathrm{~s})$ & 93 & $0-32.0$ & 2.1 & 0.244 \\
\hline \multicolumn{5}{|l|}{ Urea } \\
\hline$<7 \mathrm{mmol} / \mathrm{l}$ & 188 & $0-32.0$ & 2.1 & \\
\hline$\geq 7 \mathrm{mmol} / \mathrm{l}$ & 46 & $0-22.8$ & 1.6 & 0.573 \\
\hline \multicolumn{5}{|l|}{ Creatinine } \\
\hline$<100 \mu \mathrm{mol} / \mathrm{l}$ & 173 & $0-32$ & 2.1 & \\
\hline$\geq 100 \mu \mathrm{mol} / \mathrm{l}$ & 61 & $0-23.5$ & 1.5 & 0.411 \\
\hline \multicolumn{5}{|l|}{ Bronchoscopic interventions } \\
\hline BW only & 61 & 0 & 0 & $\mathrm{~N} / \mathrm{A}$ \\
\hline $\mathrm{BAL}$ & 7 & 0 & 0 & $\mathrm{~N} / \mathrm{A}$ \\
\hline $\mathrm{BB}$ & 18 & 0 & 0 & $\mathrm{~N} / \mathrm{A}$ \\
\hline TBNA only & 85 & $0-23.5$ & 3.4 & \\
\hline $\mathrm{TBNA}+\mathrm{EBB} / \mathrm{TBB}$ & 17 & $0-32.0$ & 5.0 & $<0.001$ \\
\hline
\end{tabular}

Note that the mean blood loss with TBB $(\mathrm{n}=6)$ was $1.8 \mathrm{ml}$ and with $\mathrm{EBB}(\mathrm{n}=11) 6.8 \mathrm{ml}(\mathrm{p}=0.230) . \mathrm{BC}=$ Bronchogenic carcinoma.

$p$ values represent the statistical difference in blood loss.

${ }^{\text {a }} \mathrm{BC}$ compared to the SVC syndrome group. ${ }^{\mathrm{b}}$ Pneumonia and other diagnosis group compared to the SVC syndrome group. ${ }^{c} \mathrm{HIV}$-reactive group compared to the rest of the study population.

Pulmonary tuberculosis (PTB) was the second most investigated disease $(23.5 \%, \mathrm{n}=55)$, whilst 22 subjects had clinical evidence of pneumonia. We did not routinely test for human immunodeficiency virus (HIV) infection, but $8.1 \%$ of the subjects $(n=19)$ had a confirmed diagnosis of HIV at the time of bronchoscopy. The re- 


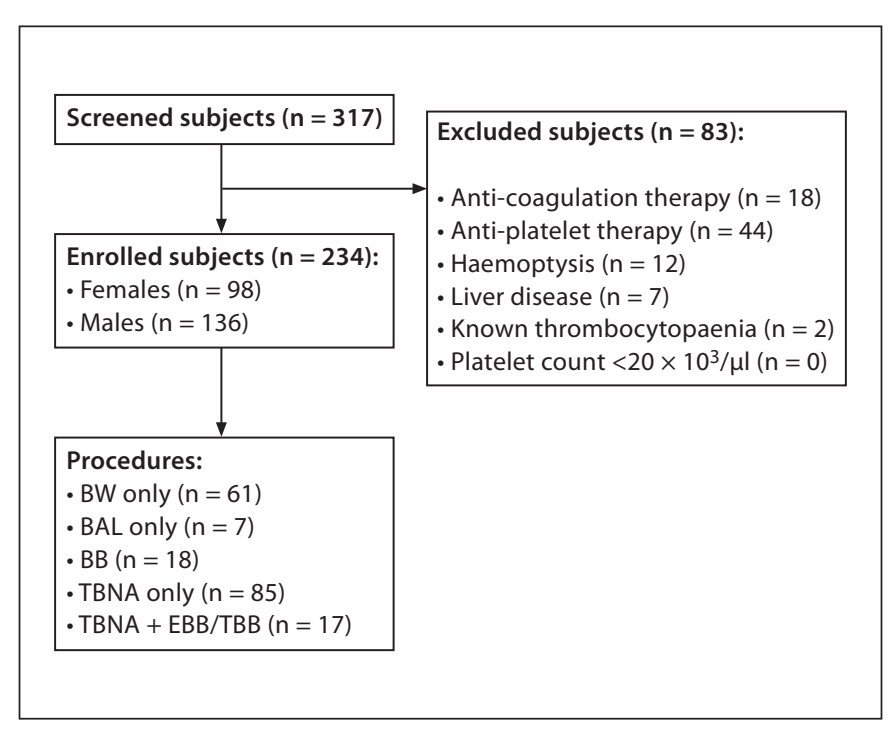

Fig. 1. Flow diagram depicting the sample selection and procedures performed.

mainder of our subjects were investigated for interstitial lung disease $(4.3 \%, \mathrm{n}=10)$ and an unconfirmed diagnosis $(6.8 \%, \mathrm{n}=16)$ at the time of bronchoscopy.

\section{Laboratory Parameters}

Our study population had a mean $\mathrm{Hb}$ of $11.87 \mathrm{~g} / \mathrm{dl}$. In total, 52 subjects (22.2\%) had an $\mathrm{Hb}$ of $\leq 10 \mathrm{~g} / \mathrm{dl}$ (mean $8.55 \mathrm{~g} / \mathrm{dl} ; \mathrm{Hb}$ range $5.3-10 \mathrm{~g} / \mathrm{dl}$ ). The lowest platelet count included in this study was $25 \times 10^{3} / \mu$ l and the highest recorded platelet count was $1,092 \times 10^{3} / \mu \mathrm{l}$, with a mean $350 \times 10^{3} / \mu$ l. Eleven subjects $(4.7 \%)$ had a platelet count $\leq 155 \times 10^{3} / \mu l$. The INR and PTT were assessed within $24 \mathrm{~h}$ in all but 26 patients (11.1\%) [these included INR specimens not done within the acceptable time period $(9.4 \%, \mathrm{n}=22)$, lost specimens $(1.3 \%, \mathrm{n}=3)$ and no patient identification on the specimen $(0.4 \%, \mathrm{n}=1)]$ and ranged from 0.80 to 1.98. PTT was found to be $\geq 30 \mathrm{~s}$ in 93 subjects (39.7\%) (PTT range 30.0-64.7 s, mean $33.8 \mathrm{~s}$ ).

Serum creatinine ranged from 49 to $622 \mu \mathrm{mol} / \mathrm{l}$. There were 61 of $234(26.1 \%)$ subjects who had a serum creatinine of $\geq 100 \mu \mathrm{mol} / \mathrm{l}$ (range $100-622 \mu \mathrm{mol} / \mathrm{l}$ ). A number of subjects $(19.7 \%, \mathrm{n}=46)$ had a serum urea value of $\geq 7$ $\mathrm{mmol} / \mathrm{l}$ (mean urea $11.2 \mathrm{mmol} / \mathrm{l}$, range $7.0-42.2 \mathrm{mmol} / \mathrm{l}$ ).

\section{Bronchoscopic Interventions}

A total of 61 subjects (26.1\%) underwent BW and 85 subjects (36.3\%) had TBNA exclusively. TBB or an EBB was done in combination with a TBNA in 17 subjects

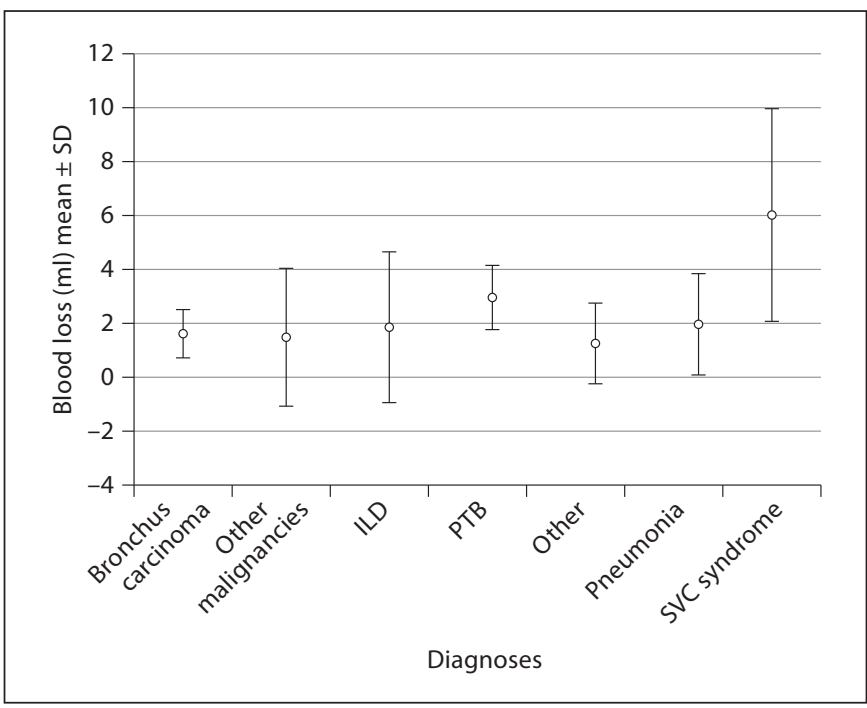

Fig. 2. The associated mean blood loss \pm standard deviations for various indications for bronchoscopy. ILD = Interstitial lung disease.

(7.1\%). The other procedures included BAL $(3.0 \%, \mathrm{n}=7)$ and $\mathrm{BB}(7.7 \%, \mathrm{n}=18)$. A majority of the subjects $(52.1 \%$, $\mathrm{n}=122$ ) had more than one procedure, with varying combinations of procedures done during the bronchoscopy.

\section{Blood Loss}

In total, 210 subjects $(89.7 \%)$ experienced minimal bleeding, 19 subjects (8.1\%) experienced mild bleeding and 5 subjects $(2.1 \%)$ experienced moderate bleeding (range 21.39-32.0 ml). No case of severe bleeding was recorded. In the group of subjects with primary lung carcinoma $(46 \%, \mathrm{n}=95)$, the total blood loss ranged from an undetected volume to $23.5 \mathrm{ml}$ (mean blood loss volume of $1.6 \mathrm{ml})$, whilst the group $(5.1 \%, \mathrm{n}=12)$ with a confirmed primary diagnosis of a malignancy other than bronchogenic carcinoma had a mean bleeding of $1.5 \mathrm{ml}$ (fig. 2).

Those subjects $(2.1 \%, \mathrm{n}=5)$ with SVC syndrome had blood loss ranging from undetected to a high of $16.3 \mathrm{ml}$ (mean blood loss of $6.0 \mathrm{ml}$ ), being statistically significantly higher than subjects with a diagnosis of bronchogenic carcinoma without SVC syndrome $(p=0.033)$ or other diagnosis $(p=0.026)$. All 5 subjects had TBNAs done during bronchoscopy and only 1 subject also had an EBB. Laboratory parameters included a mean $\mathrm{Hb}$ of $11.8 \mathrm{~g} / \mathrm{dl}$ (range $7.8-15.1 \mathrm{~g} / \mathrm{dl}$ ), a mean platelet count of $524 \times$ $10^{3} / \mu \mathrm{l}$ (range $284-701 \times 10^{3} / \mu \mathrm{l}$ ) and a mean INR of 1.19 (range 1.16-1.21). None of these 5 subjects was tested for HIV infection. 
Blood loss volume ranged from undetected to $16.3 \mathrm{ml}$ (mean $2.9 \mathrm{ml}$ ) in those subjects investigated for PTB $(23.5 \%, \mathrm{n}=55)$. Where there was clinical evidence of pneumonia $(9.4 \%, \mathrm{n}=22)$, the mean blood loss was only $1.9 \mathrm{ml}$. The blood loss in the HIV-positive group ranged from undetected to a maximum of $6.9 \mathrm{ml}$ (mean blood loss $1.9 \mathrm{ml}$ ). Statistically, there was no difference in blood loss between the HIV-positive and the unknown HIV status groups ( $\mathrm{p}=0.951)$. In the remainder of our subjects, including those with interstitial lung disease $(4.3 \%, \mathrm{n}=$ $10)$, the recorded total blood loss was no more significant than the above-mentioned subgroups.

In the group $(22.2 \%, \mathrm{n}=52)$ with $\mathrm{Hb} \leq 10 \mathrm{~g} / \mathrm{dl}$, the blood loss volume ranged from undetected to $23.4 \mathrm{ml}$ (mean bleeding $2.3 \mathrm{ml}$ ). Amongst the remaining subjects $(77.3 \%, \mathrm{n}=182)$ with an $\mathrm{Hb}>10 \mathrm{~g} / \mathrm{dl}$, bleeding ranged from undetected to a maximum of $32 \mathrm{ml}$ (mean blood loss $1.9 \mathrm{ml}, \mathrm{p}=0.551$ ).

In patients with a platelet count of $\leq 155 \times 10^{3} / \mu \mathrm{l}$ $(4.7 \%, \mathrm{n}=11)$, the highest recorded blood loss was 3.3 $\mathrm{ml}-$ in a subject with a platelet count of $144 \times 10^{3} / \mu \mathrm{l}$. The subject with a platelet count of $25 \times 10^{3} / \mu \mathrm{l}$ had had a BW as well as a TBB and only lost a total of $1.6 \mathrm{ml}$ of blood.

The blood loss in those subjects without an INR (11.1\%, $\mathrm{n}=26$ ) ranged only from undetected to $6.3 \mathrm{ml}$ (mean blood loss $2.5 \mathrm{ml})$. In those subjects $(88.9 \%, \mathrm{n}=208)$ who had an INR recorded appropriately, we found no statistical difference between those with an INR $<1.3$ (84.6\%, $\mathrm{n}=198)$ and those with an INR $>1.3(4.3 \%, \mathrm{n}=10)(\mathrm{p}=$ $0.903)$. A mean blood loss of $2.1 \mathrm{ml}$ occurred in those subjects with an abnormal PTT (39.4\%, $\mathrm{n}=93$ subjects), and $1.3 \mathrm{ml}(\mathrm{p}=0.244)$ in those with a PTT measurement of $<30 \mathrm{~s}$. Renal dysfunction (both in terms of a serum creatinine $\geq 100 \mu \mathrm{mol} / \mathrm{l}$ or a serum urea $>7 \mathrm{mmol} / \mathrm{l}$ ) did not predict bleeding.

\section{Discussion}

We found no severe bleeding in this cohort of patients pre-selected to have a low clinical risk of bleeding. In fact, there were only 5 cases of moderate bleeding. Moreover, our study, although not specifically designed to do so, suggested that clinical screening and a platelet count of $\geq 20 \times 10^{3} / \mu$ lalone may be sufficient to identify low-risk patients, although further studies are needed to test this hypothesis. Only the presence of SVC syndrome and the addition of $\mathrm{EBB}$ and TBB to TBNA were associated with an increased risk of bleeding.
Attempts at correlating the risk of bleeding and the underlying clinical condition of the patient, as well as the coagulation profiles of patients undergoing bronchoscopic intervention, have been made $[3,5,6,10,16,17]$. The overall incidence of blood loss encountered during bronchoscopy has, however, not been prospectively described for the routine bronchoscopic intervention on stable, low-risk patients needing further investigations.

The low incidence of clinically significant bleeding evident in our study compares favourably with previous studies $[1,2]$. A recent randomised trial reported that the complications encountered in 168 patients included a 16.5 and $2.3 \%$ incidence of minor $(20-50 \mathrm{ml})$ and major bleeding (50-100 ml), respectively [18]. The authors however only relied on visual estimations of blood loss and did not accurately measure the absolute blood loss which may have been overestimated.

There is a paucity of prospective data on the use of bronchoscopy in the clinical setting of SVC syndrome $[19,20]$. Experienced bronchoscopists usually exercise a particular level of care when there is evidence of SVC syndrome, a clinical picture largely created by engorged vasculature due to obstruction of the larger venous vessels within the thoracic cage [21]. This careful approach to an engorged bronchial tree has been validated by our data. Any minor manipulations of endobronchial lesions or TBB in SVC syndrome may lead to bleeding and this may have been illustrated in the tendency for an increased mean blood loss volume, although only amounting to 6.0 $\mathrm{ml}$ compared to all other subgroups in this study. SVC syndrome may be detected on clinical screening, and may thus validate our proposal that a clinical history and examination could accurately identify those subjects at a higher risk of bleeding, although, at most, only mild bleeding was observed in our study. Furthermore, a very recent study from our institution in patients with chest malignancies and SVC syndrome confirmed the excellent safety of diagnostic bronchoscopy in this setting [22].

There is conflicting evidence regarding the current generally accepted risk factors for bleeding associated with bronchoscopy and some risk factors have been challenged. Herth et al. [8] found that aspirin does not increase bleeding complications during bronchoscopy. Though performed on an animal model, Brickey [9] demonstrated that even extreme INR $>10$ do not correlate with an increased risk of bleeding during TBB. In a study conducted on 24 thrombocytopaenic patients (mean platelet count $30 \times 10^{3} / \mu \mathrm{l}$, range $\left.7-60 \times 10^{3} / \mu \mathrm{l}\right)$, Papin et al. [5] observed a $20.8 \%(n=5)$ incidence of significant bleeding after TBB, including one death from massive en- 
dobronchial haemorrhage (platelet count $23 \times 10^{3} / \mu \mathrm{l}$ ), despite platelet transfusions during and immediately after bronchoscopy. The thrombocytopaenia ranged from $7-32 \times 10^{3} / \mu \mathrm{l}$ (mean platelet count $20 \times 10^{3} / \mu \mathrm{l}$ ) in these 5 subjects and was due to chemotherapy or malignant bone marrow invasion. Coagulation studies have no predictive value in detecting who may or may not bleed during bronchoscopy $[3,16,17]$. We did not find an incidental platelet count $<20 \times 10^{3} / \mu$ in our study population; the subject with the lowest platelet count $\left(25 \times 10^{3} / \mu \mathrm{l}\right)$ had only a minimal blood loss. Three other subjects with severe thrombocytopaenia (platelet counts of $<50 \times$ $10^{3} / \mu \mathrm{l}$ ) had an undetected blood loss calculated by the plasma low $\mathrm{Hb}$ apparatus. The difference in blood loss between those patients with a thrombocytopaenia and those with normal platelet counts was statistically insignificant and may also imply that, on a clinical basis, even these patients may have no history of excessive bleeding and have a normal examination.

In our sample patients at a low risk of bleeding on clinical grounds, all had platelets of $>25 \times 10^{3} / \mu$ l, and none of the patients within the thrombocytopenic range of 25 $155 \times 10^{3} / \mu$ l suffered serious blood loss. A much larger study in mildly thrombocytopenic patients would be needed to assess the ability of an accurate clinical assessment alone, in order to determine the risk of bleeding in patients with a low clinical risk of bleeding during bronchoscopy.

In an attempt to predict which patients are at risk for bleeding during flexible bronchoscopy, anticoagulation studies have been used excessively in routine practice, although there is no convincing evidence to show that these predict bleeding [13]. Kozak and Brath [16] conducted a retrospective analysis of 305 fiberoptic bronchoscopies with biopsy. Routine measurements of the prothrombin time did not predict bleeding complications during fiberoptic bronchoscopy with biopsy. Bjørtuft et al. [3] prospectively evaluated bleeding parameters in 104 consecutive TBB. The conclusion was that coagulation studies could not predict clinically significant bleeding. In a similar larger prospective case series, Zahreddine et al. [17] evaluated the predictive potential of coagulation studies in 426 bronchoscopies. Here, once again, abnormal coagulation tests did not predict bleeding during the procedure. Lastly, a recent meta-analysis by Segal and Dzik [23] found insufficient evidence to conclude that abnormal coagulation test results predict bleeding. Conversely, our findings indicate that a careful clinical evaluation resulted in a low incidence of bleeding in a population of subjects deemed to be at a low risk of bleeding.
In the instance of acute or chronic renal failure, the associated bleeding tendencies have been previously well described; there is a particular risk of gastrointestinal bleeding [24]. Certainly from our data, as well as in previous studies, there is no clear risk of bleeding during bronchoscopy solely due to impaired renal function and the accumulation of blood urea and nitrogenous waste products [25].

In previous studies, many tissue samples taken during bronchoscopy may have been obtained using tissue forceps $[6,10,11]$. In our study, we predominantly used the minimally invasive TBNA procedure. Although a statistically significant difference was found when comparing the EBB/TBB group with the TBNA group, the clinical significance may seem irrelevant as the absolute amount of blood loss in both groups was $<10 \mathrm{ml}$. In our study, most of the diagnoses were made using TBNA, and so it cannot be directly compared to previous studies where $\mathrm{EBB} / \mathrm{TBB}$ were predominantly used.

The major strength of our study is that we accurately measured the $\mathrm{Hb}$ concentration and the volume of all specimens aspirated from the bronchial tree during flexible bronchoscopy with its associated interventions in order to determine the actual blood loss, and that we did not use visual estimation. Other strengths include having an independent bronchoscopist, thus avoiding a potential operator-associated bias.

One limitation of our observational study is the relatively small sample size. However, as we only observed an overall incidence of $2 \%$ moderate bleeding and all of our routine bronchoscopic techniques were used at least 7 times, we terminated the study. We found that patients who underwent EBB and/or TBB in addition to TBNA bleed significantly more. The fact that only 17 patients underwent these procedures can therefore be viewed as another potential limitation. Interestingly, in this subgroup, mean blood loss with TBB was only $1.8 \mathrm{ml}$, which was not significantly less than with EBB $(6.8 \mathrm{ml}, \mathrm{p}=$ 0.230 ). Moreover, we did not observe one single severe bleeding. Although we accurately documented the volume of blood loss, the clinical consequences of such an event may be a more relevant outcome.

Only a prospective multi-centre randomised study with a non-inferiority design and with a sample size far in excess of that of our study population would be able to confirm whether routine coagulation studies are indeed redundant.

In conclusion, we observed only mild-to-moderate bleeding in this cohort of patients pre-selected to have a low clinical risk of bleeding. Only the presence of SVC 
syndrome and the addition of $\mathrm{EBB}$ and TBB to TBNA were associated with an increased risk of bleeding. Moreover, our data suggested that clinical screening and a platelet count $\geq 20 \times 10^{3} / \mu$ l may be sufficient to identify low-risk patients, although further studies are needed to test this hypothesis.

\section{Acknowledgements}

We would like to thank HemoCue for kindly sponsoring the HemoCue Plasma Low $\mathrm{Hb}$ apparatus for the duration of our study. We also thank Professor Martin Kidd and Mr. Justin Harvey for their assistance with statistical analysis.

\section{References}

$\checkmark 1$ Cordasco EM Jr, Mehta AC, Ahmad M: Bronchoscopically induced bleeding - a summary of nine years' Cleveland clinic experience and review of the literature. Chest 1991;100:1141-1147.

-2 Hanson KR, Zavala DC, Rhodes ML: Transbronchial biopsy via flexible bronchoscope: results in 164 patients. Am Rev Respir Dis 1976;114:67-72.

>3 Bjørtuft O, Brosstad F, Boe J: Bronchoscopy with transbronchial biopsies: measurement of bleeding volume and evaluation of the predictive value of coagulation tests. Eur Respir J 1998;12:1025-1027.

4 Thornton J: Estimation of blood loss during surgery. Ann R Coll Surg Engl 1963;33:164174.

$>5$ Papin TA, Lynch JP, Weg JG: Transbronchial biopsy in the thrombocytopenic patient. Chest 1985;88:549-552.

6 Papin TA, Grum CM, Weg JG: Transbronchial biopsy during mechanical ventilation. Chest 1986;89:168-170.

7 Zavala DC: Pulmonary hemorrhage in fiberoptic transbronchial biopsy. Chest 1976;70: 584-588.

$>8$ Herth FJ, Becker HD, Ern A: Aspirin does not increase bleeding complications after transbronchial biopsy. Chest 2002;122:14611464.
9 Brickey DA, Lawlor DP: Transbronchial biopsy in the presence of profound elevation of the international normalized ratio. Chest 1999;115:1667-1671.

10 Schulman LL, Smith CR, Drusin R, Rose EA, Enson Y, Reemtsma K: Utility of airway endoscopy in the diagnosis of respiratory complications of cardiac transplantation. Chest 1988;93:960-967.

11 Diaz-Guzman E, Vadi S, Minai OA, Gildea TR, Mehta AC: Safety of diagnostic bronchoscopy in patients with pulmonary hypertension. Respiration 2009;77:292-297.

12 Bushick JB, Eisenberg JM, Kinman JK: Pursuit of abnormal coagulation screening tests generates modest hidden preoperative costs. J Gen Intern Med 1989;4:493-497.

13 Kitchens CS: Preoperative PTs, PTTs, costeffectiveness, and health care reform. Radical changes that make good sense. Chest 1994;106:661-662.

14 Kitchens CS: A stuck pig - even on warfarin - doesn't always bleed. Chest 1999;115:14921493.

15 Chinsky K: Bleeding risk and bronchoscopy: in search of the evidence in evidence-based medicine. Chest 2005;127:1875-1877.

16 Kozak EA, Brath LK: Do 'screening' coagulation tests predict bleeding in patients undergoing fiberoptic bronchoscopy with biopsy? Chest 1994;106:703-705.

-17 Zahreddine I, Atassi K, Fuhrman C: Impact of prior biological assessment of coagulation on the hemorrhagic risk of fiberoptic bronchoscopy. Rev Mal Respir 2003;20:341-346.
18 Ernst A, Herth F: Effect of routine clopidogrel use on bleeding complications after transbronchial biopsy in humans. Chest 2006;129:734-737.

19 Koegelenberg CFN, Diacon AH: Diagnostic yield and safety of ultrasound-assisted biopsies in superior vena cava syndrome. Eur Respir J 2009;33:1389-1395.

20 Selcuk ZT, Firat P: The diagnostic yield of transbronchial needle aspiration in superior vena cava syndrome. Lung Cancer 2003;42: 183-188.

21 Abner A: Approach to the patient who presents with superior vena cava obstruction. Chest 1993;103:394S-397S.

22 Brundyn K, Koegelenberg CFN, Diacon AH, Louw M, Schubert P, Bolliger CT, van den Heuvel MM, Wright CA: Transbronchial fine needle aspiration biopsy and rapid onsite evaluation in the setting of superior vena cava syndrome. Diagn Cytopathology 2011, E-pub ahead of print.

23 Segal JB, Dzik WH: Paucity of studies to support that abnormal coagulation test results predict bleeding in the setting of invasive procedures: an evidence-based review. Transfusion 2005;45:1413-1425.

24 Lengani A, Zech P: Epidemiology of severe chronic renal insufficiency in Burkina Faso. Sante 1997;7:379-383.

25 Kallay N, Haponik EF: Hemoptysis in patients with renal insufficiency: the role of flexible bronchoscopy. Chest 2001;119:788794. 